\title{
Role of the Renal Microcirculation in Progression of Chronic Kidney Injury in Obesity
}

\author{
Alejandro R. Chade ${ }^{a-c}$ John E. Hall ${ }^{a, d}$ \\ ${ }^{a}$ Department of Physiology and Biophysics, Center for Excellence in Cardiovascular-Renal Research, ${ }^{b}$ Department of \\ Medicine, ${ }^{\mathrm{C}}$ Department of Radiology, and ${ }^{\mathrm{d}}$ Mississippi Center for Obesity Research, University of Mississippi Medical \\ Center, Jackson, Miss., USA
}

\section{Key Words}

Kidney · Adipose · Endothelium · Inflammation ·

Angiogenesis · Metabolic

\begin{abstract}
Background: Obesity is largely responsible for the growing incidence and prevalence of diabetes, cardiovascular and renal diseases. Current strategies to prevent and treat obesity and its consequences have been insufficient to reverse the ongoing trends. Lifestyle modification or pharmacological therapies often produce modest weight loss which is not sustained and recurrence of obesity is frequently observed, leading to progression of target organ damage in many obese subjects. Therefore, research efforts have focused not only on the factors that regulate energy balance, but also on understanding mechanisms of target organ injury in obesity. Summary and Key Message: Microvascular (MV) disease plays a pivotal role in progressive kidney injury from different etiologies such as hypertension, diabetes, and atherosclerosis, which are all important consequences of chronic obesity. The MV networks are anatomical units that are closely adapted to specific functions of nutrition and removal of waste in every organ. Damage of the small vessels in several tissues and organs has been reported in obesity and may increase cardio-renal risk. However, the mechanisms by
\end{abstract}

which obesity and its attendant cardiovascular and metabolic consequences interact to cause renal MV injury and chronic kidney disease are still unclear, although substantial progress has been made in recent years. This review addresses potential mechanisms and consequences of obesity-induced renal MV injury as well as current treatments that may provide protection of the renal microcirculation and slow progressive kidney injury in obesity.

두 2016 S. Karger AG, Basel

\section{Introduction}

The worldwide population is not only growing in numbers but also in size. Overweight and obesity are the major epidemics of the 20th and 21 st centuries. Although recent epidemiologic assessments may suggest a slowdown, they also show that growth in obesity is in the upslope of its trajectory and prevalence is steady or increasing in developed and developing countries, among men and women, children, adolescents and adults $[1,2]$. Obesity should be one of the most preventable diseases but it is evident that recent and current educational efforts have failed to counteract current trends. Therefore, we are now facing the impact and consequences of obesity as a major risk factor and cause for cardiovascular,

\section{KARGER}

E-Mail karger@karger.com

www.karger.com/ajn
(C) 2016 S. Karger AG, Basel

0250-8095/16/0445-0354\$39.50/0
Prof. Alejandro R. Chade, MD, FAHA

Department of Physiology and Biophysics, Department of Medicine Department of Radiology, University of Mississippi Medical Center 2500 North State Street, Jackson MS 39216-4505 (USA)

E-Mail achade@umc.edu 
renal, gastrointestinal, metabolic and rheumatic diseases, with a tremendous impact on quality of life and healthcare costs.

Recent statistics from the Centers for Disease Control [3], the National Institutes of Health [4] and the World Health Organization [5] show that obesity has more than doubled since 1980 and almost 2 billion adults worldwide are overweight or obese. Currently, $68.8 \%$ of adults in the US are overweight or obese [4] at higher risk of developing life-threatening consequences; at least $35 \%$ of adults are obese and $6-8 \%$ have extreme obesity (body mass index (BMI) over 40). The prevalence of obesity is slightly higher in women than men (40.4 vs. 35\%) [2]. Another frightening statistic is that is that over $33 \%$ of children and adolescents in the US are overweight and over $18 \%$ are obese $[3,4]$. Since approximately $80 \%$ of obese children become obese adults, it is likely that the prevalence of obesity and associated cardiovascular, metabolic and kidney diseases will continue to increase unless these trends can be reversed. Therefore, we can assume that over two-thirds of the population is at higher risk of developing life-threatening consequences of overweight and obesity.

\section{Obesity as a Major Risk Factor for Chronic Kidney Disease}

The global increase in chronic kidney disease (CKD) parallels the obesity epidemic. Obesity is widely recognized to increase the risk for development of CKD through diabetes and hypertension which together account for more than $70 \%$ of end-stage renal disease (ESRD) [6]. Obesity also increases the risk of CKD in the absence of known cardiovascular risk factors or underlying nephropathy [7] and is therefore considered an independent risk factor for development of renal dysfunction and injury that can progress toward CKD and ESRD [8, 9]. Obesity may be one of the most preventable etiologies of CKD as the prevalence of CKD doubles in the obese compared to lean subjects [10]. Obesity can also exacerbate the development and progression of renal injury in other forms of renal disease such as IgA nephropathy [11] or amyloidosis [12].

In a retrospective analysis of 320,252 adults followed for 15-35 years, the rate of ESRD rose progressively as BMI increased and this relationship remained after adjustment for blood pressure, diabetes, smoking, age and several other variables [13]. Abdominal obesity is even more closely associated with CKD than overall adiposity or increased BMI [14]. Moreover, individuals with 'fatty kidneys' (high renal sinus fat levels) had a higher risk for CKD even after adjustment for BMI and visceral adiposity [15]. Thus, increased adiposity, especially when it is localized in and around the kidneys, may contribute to CKD and ESRD, although the mechanisms involved are not fully understood.

While there is considerable evidence for a major role of obesity as a risk factor for CKD/ESRD, the direct pathophysiological links between obesity and CKD are still unclear due to the potential confounding effects of cardiovascular risk factors like diabetes and hypertension, which are frequently associated with obesity [7]. The effects of hypertension and diabetes in promoting renal injury in the context of obesity has been discussed in other publications [16, 17]; therefore, we will mainly discuss obesitydriven mechanisms of renal injury that may be independent of diabetes, hypertension or primary kidney disease from other etiologies.

\section{Mechanisms of Obesity-Induced Kidney Injury}

The potential mechanisms of progressive renal injury in obesity are multifold. From physical compression of the kidneys to upregulation of several injurious pathways, the kidneys are vulnerable to progressive dysfunction and evolving parenchymal damage. Pathways, in addition to hypertension and diabetes, by which obesity may cause renal dysfunction and injury include glomerular hyperfiltration, increased glomerular capillary wall tension, metabolic abnormalities (dyslipidemia and altered glucose metabolism without overt diabetes), glomerular and tubular lipid accumulation (lipotoxicity), all of which may lead to structural and functional changes of mesangial cells, proximal tubular cells and podocytes and a gradual reduction in nephron number [18-20]. In addition, increased systemic and renal oxidative stress, increased generation of inflammatory cytokines from adipose tissues, renal inflammation and progressive renal microvascular (MV) dysfunction are prominent pathological processes for progression of renal injury in obesity [21-23].

\section{Obesity and Renal Microcirculation}

MV networks are highly regulated, providing nutrition and removing waste products to meet the specific metabolic needs of each tissue. In the kidneys, the glo- 
merular and peritubular capillaries carry additional indispensable burdens of glomerular filtration, tubular reabsorption and systemic recirculation of vital body fluids, nutrients, hormones and other substances. Endothelial dysfunction, vascular remodeling and loss of the renal microvessels play a prominent role in inducing renal injury associated with major cardiovascular risk factors such as hypertension, dyslipidemia, diabetes and atherosclerosis [24-27].

Increased glomerular hydrostatic pressure and renal MV endothelial dysfunction contribute to increased glomerular capillary wall permeability and development of albuminuria, which promote glomerular capillary loss and further increases in intraglomerular pressure in a positive feedback fashion [28]. Furthermore, the damage and loss of the small vessels in glomeruli and peritubular capillaries have been suggested as important mediators for the progression of renal injury [29]. Although focal segmental glomerulosclerosis and nephron loss may develop slowly, these changes are often progressive and can lead to severe CKD and eventually ESRD in many obese patients [30].

In the next sections we focus on the role of renal MV dysfunction and damage in development of obesity-induced renal injury and the mechanisms underlying such changes. We also briefly discuss potential strategies that may protect the kidney MV architecture and function.

\section{Potential Mechanisms of Obesity-Induced MV Abnormalities}

Microcirculatory dysfunction occurs throughout the body in obesity. For example, dysfunction of the small vessels at the level of both the resistance vessels and the nutritive capillaries beds in skeletal muscle or skin begins at an early age and primary stages of obesity and develops progressively as adiposity increases, resulting in endothelial dysfunction and progressive vascular remodeling [31-33]. Therefore, it is likely that some of the mechanisms leading to MV abnormalities are also activated in the kidney, which is exposed to obesity.

Obesity may augment the risk for CKD initially by increasing renal tubular reabsorption and metabolic rate which lead to compensatory renal vasodilation, glomerular hyperfiltration, higher glomerular capillary pressures and glomerular hypertrophy [34]. Although the renal hemodynamic changes and increased glomerular filtration rate (GFR) initially offset the increased tubular reabsorption and permit balance between intake and output of salt and water, which have to be maintained, in the long term, the mechanical strain on the glomerular capillaries likely cause slow development of injury and rarefaction [35].

Through adipose tissue build up in and around the kidneys and intrarenal accumulation of extracellular matrix (ECM), the kidney is also exposed to constant compressive forces that may stimulate the renin-angiotensin aldosterone system and increase tubular reabsorption, leading to increased blood pressure $[35,36]$. Physical compression of the kidneys appears to occur in obese humans, dogs and rabbits [16] but may not equally develop in rodent models of obesity. Indeed, the kidneys appear to be 'floating' in the excessive adipose tissue, rather than being compressed, in genetically modified and diet-induced rodent models of obesity [35].

In addition to compressing the kidneys, the fat surrounding the kidneys may be a source of stem cells and inflammatory, pro-fibrotic and angiogenic cytokines. Other 'lipotoxic' effects of perinephric fat and infiltration of lipids in the renal parenchyma may play contributory roles in the development of renal injury.

\section{Extra- and Intrarenal Adipose Tissue: Not Just a Fat Storage}

Development of obesity and accumulation of abdominal and visceral fat are highly related with adverse renal outcomes. Adipose tissues are not only sites of energy storage, but also a rich source of products that have effects on surrounding and distal tissues. Adipose tissues are endocrine and immunologically active organs with numerous effects on regulation of systemic energy homeostasis, inflammatory responses and are rich in immune cells that may be involved in obesity-mediated metabolic complications, including insulin resistance. The immune functions of adipose tissue are beyond the scope of this section and readers are suggested to consult elegant up-to-date published articles [37-41].

Recent studies showed that adipose tissue is also an accessible source of mesenchymal stem cells that their pluripotency can be manipulated and applied for therapeutic purposes in the heart $[42,43]$, kidney $[44,45]$ and other organs [46-49]. Adipose-derived stem cells are as effective as bone marrow-derived stem cells but with the relative advantage of being easier to access. The healing effects of adipose-derived stem cell therapy include neovascularization and vascular repair leading to amelioration of tissue injury. Importantly, evidence also supports the possibility that adipose-derived progenitor cells may modulate oxidative stress, secrete various cytokines and growth factors with immunomodulatory, angiogenic, anti-inflammatory 
and anti-apoptotic effects, attenuating inflammation and tissue loss [50], although some of these effects may be tissue or milieu-specific [51]. However, despite a potential increase in the source of adipose-derived stem cells, renal injury still develops and progresses in obese patients, suggesting additional mechanisms that may interfere with these beneficial effects of adipose tissue.

Adipose tissue also serves as a source for angiogenic cytokines, which may have effects that are not limited to vascular proliferation. For example, vascular endothelial growth factor (VEGF), a major angiogenic factor, stimulates the conversion of white fat to brown fat and reduces insulin resistance, suggesting multiple autocrine and paracrine effects that go beyond angiogenesis and participate in metabolic pathways [52-55]. On the other hand, inhibitory isoforms of VEGF such as VEGF-165b are also upregulated in obesity, counteracting the proangiogenic effects and promoting vascular rarefaction in adipose tissue [56]. Thus, it is possible that the obesity milieu determines whether VEGF acts as a compensatory or pathological factor on the vasculature of adipose tissue and the kidneys. These findings highlight the complexity of the VEGF pathway and the challenge of determining whether VEGF may be a therapeutic target in obesity.

There are major functional differences of adipocytes related to their anatomical location in visceral or subcutaneous fat. Visceral adipose tissue and its adipose-tissue resident macrophages produce less adiponectin and more pro-inflammatory cytokines like tumor necrosis factoralpha (TNF- $\alpha$ ) and interleukin-6 (IL-6), which can induce insulin resistance and promote endothelial dysfunction [57]. Fat can infiltrate the kidneys and it is possible that the enhanced pathologic profile of visceral fat has a greater potential to increase cardiometabolic risk, propensity to hypertension and the risk for CKD more than subcutaneous fat $[15,58,59]$.

Thus, although stem pluripotent cells are developed and stored in adipose tissue, type and distribution of adiposity may influence the development of MV abnormalities in various organs, including the kidneys, during obesity. It is unknown whether 'resident' adipose-derived stem cells may endogenously mobilize to the kidney in obesity but if they do, the inability to regenerate following injury suggests that these healing mechanisms may be overwhelmed. Alternatively, it is possible that based on their different biochemical profile, adipose tissues outside the kidney and fat infiltration into the renal parenchyma represent competing forces. Adipose tissue may not only serve as a source of numerous cytokines, but can also modulate their effects on mobilization and actions of renal resident mesenchymal cells toward physiological cell turnover [60,61], pathological angiogenesis [62], reparative angiogenesis [63] or vascular rarefaction and tissue damage [64].

\section{Obesity-Induced Inflammation as a Promoter of Vascular Proliferation}

Obesity is a chronic low-grade inflammatory condition in which adipose tissue (mainly visceral) serves as the source of inflammatory cytokines, as stated earlier. Experimental and clinical studies demonstrated that obesity-induced inflammation develops in the heart $[65,66]$, liver [67], large and small vessels [68, 69], brain [70] and kidneys $[21,71]$. It is unclear whether development of inflammation accelerates or increases in parallel with obesity, but there is evidence that inflammation develops early and rapidly after excessive weight gain is sustained and may contribute to obesity-induced organ injury [72].

Significant renal MV dysfunction parallels chronic inflammation in obese subjects. Our study [21] using adult obese Zucker rats (OZR) as a model of obesity showed that systemic and renal inflammation progressively develops, which is paralleled by progressive renal dysfunction, fibrosis and significant increases in cortical and medullary MV density (fig. 1). To dissect the role of aging from obesity in these pathological changes, we performed these studies in young (12 weeks) and adult (32 weeks) OZR and their lean counterparts. We observed that proinflammatory cytokines such IL- 6 and TNF- $\alpha$ as well as renal inflammatory infiltrates progressively increased with obesity. Lean Zucker rats of the same age did not show such changes indicating that obesity, rather than aging, was the major driving force behind inflammation and progressive renal injury [21].

Inflammation-driven neovascularization [73] might reflect a compensatory mechanism to sustain the perfusion of injured or ischemic tissues. Despite increased renal MV density, OZR displayed reduced renal blood flow and GFR and increased proteinuria [21]. This finding suggests that renal neovascularization/angiogenesis in the OZR could be a compensatory but insufficient and eventually dysfunctional response subsequent to factors that cause kidney dysfunction and/or kidney injury. Evidence supporting direct and intermediate actions of TNF- $\alpha$ and IL- 6 as powerful instigators of angiogenesis has been shown in several pathological conditions [74-78]. Furthermore, inflammation in obesity may also be driven by augmented activity of other angiogenic pro-inflammatory cytokines such as IL-8, monocyte chemoattractant protein-1 or nuclear factor kappa B, to name a few [79-84]. 


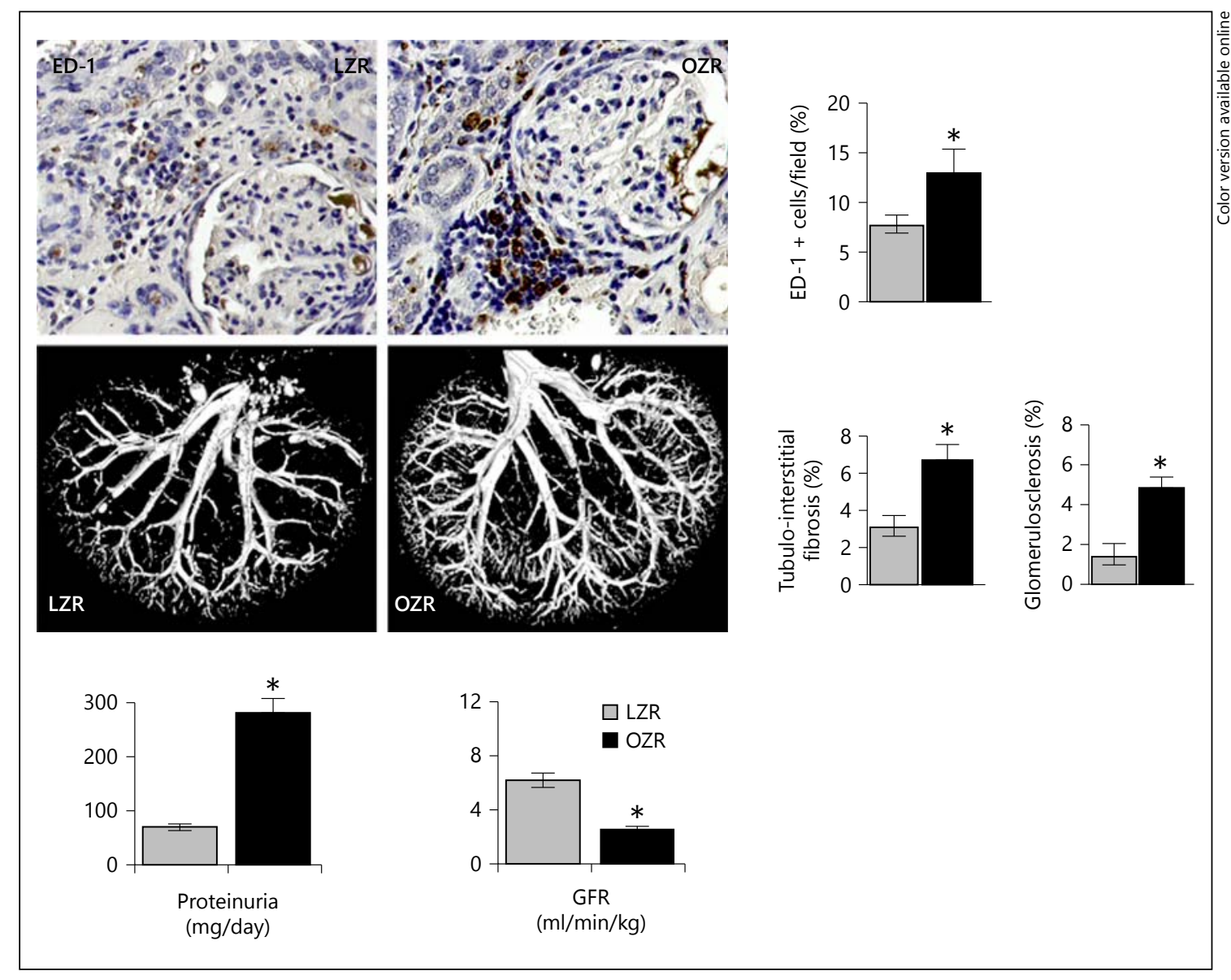

Fig. 1. Top: representative renal cross sections from adult LZR and OZR, respectively showing inflammatory infiltrates, and quantification (percent of ED-1 + macrophages). Middle: representative $3 \mathrm{D}$ micro-CT reconstruction of the renal microvasculature, and quantification of the renal fibrosis in adult LZR and OZR. Bottom: representative bar graphs showing proteinuria and GFR from adult LZR and OZR. Increased renal MV density in OZR was accompanied by increased inflammation, renal dysfunction and injury, suggesting pathological neovascularization. Grey bars: LZR, black bars: OZR. * $\mathrm{p}<0.05$ vs. LZR. Reproduced and modified from Iliescu and Chade [21]. LZR = Lean Zucker rats.
We also observed renal neovascularization in a swine model of chronic dyslipidemia, which promotes increased TNF- $\alpha$ and an inflammatory milieu in the kidneys. Using this model, we showed that inhibiting TNF- $\alpha$ led to decreased vascular proliferation and a decrease in basal renal hemodynamics [85]. These findings support the notion that inflammation-induced neovascularization might be a compensatory mechanism initially aimed at preserving renal perfusion in dyslipidemia. However, as in obesity, inflammation-driven neovascularization may result in dysfunctional or immature vessels with blind ends or loose endothelial junctions that increase vascular permeability and prevent adequate responses to changes in vascular tone, leading to abnormal removal of toxins and facilitating extravasation of injurious cytokines [85-87]. These de- fects in newly generated vessels may further contribute to progression of renal injury as chronic inflammation is perpetuated in obesity. Therefore, it is possible that renal neovascularization in obesity (or dyslipidemia) is largely driven by inflammation and may act as a double-edged sword, that is, it may initially help to preserve renal hemodynamics but later contribute to functional and structural parenchymal damage due to significant MV abnormalities.

\section{Renal Fibrosis as Promoter of MV Remodeling}

Fibrosis results from replacement of normal, functioning renal parenchyma with scar tissue. Renal fibrosis is the common final stage of CKD/ESRD, regardless of eti- 
Fig. 2. Schematic illustration of the potential mechanisms of obesity-induced renal injury. Multiple injurious pathways for the kidney are activated by direct effects of obesity and visceral fat, leading to a progressive deterioration of renal function, MV rarefaction in the glomerular and peritubular compartments, and consequent development of progressive renal dysfunction and injury. SNS = Sympathetic nervous system; RAAS = renin-angiotensin aldosterone system; NFKB = nuclear factor kappa B; MCP-1 = monocyte-chemoattractant protein-1; TGF- $\beta=$ transforming growth factor $-\beta$; CTGF $=$ connective tissue growth factor; FGF = fibroblast growth factor; TIMPs = tissue inhibitors of metalloproteinases.

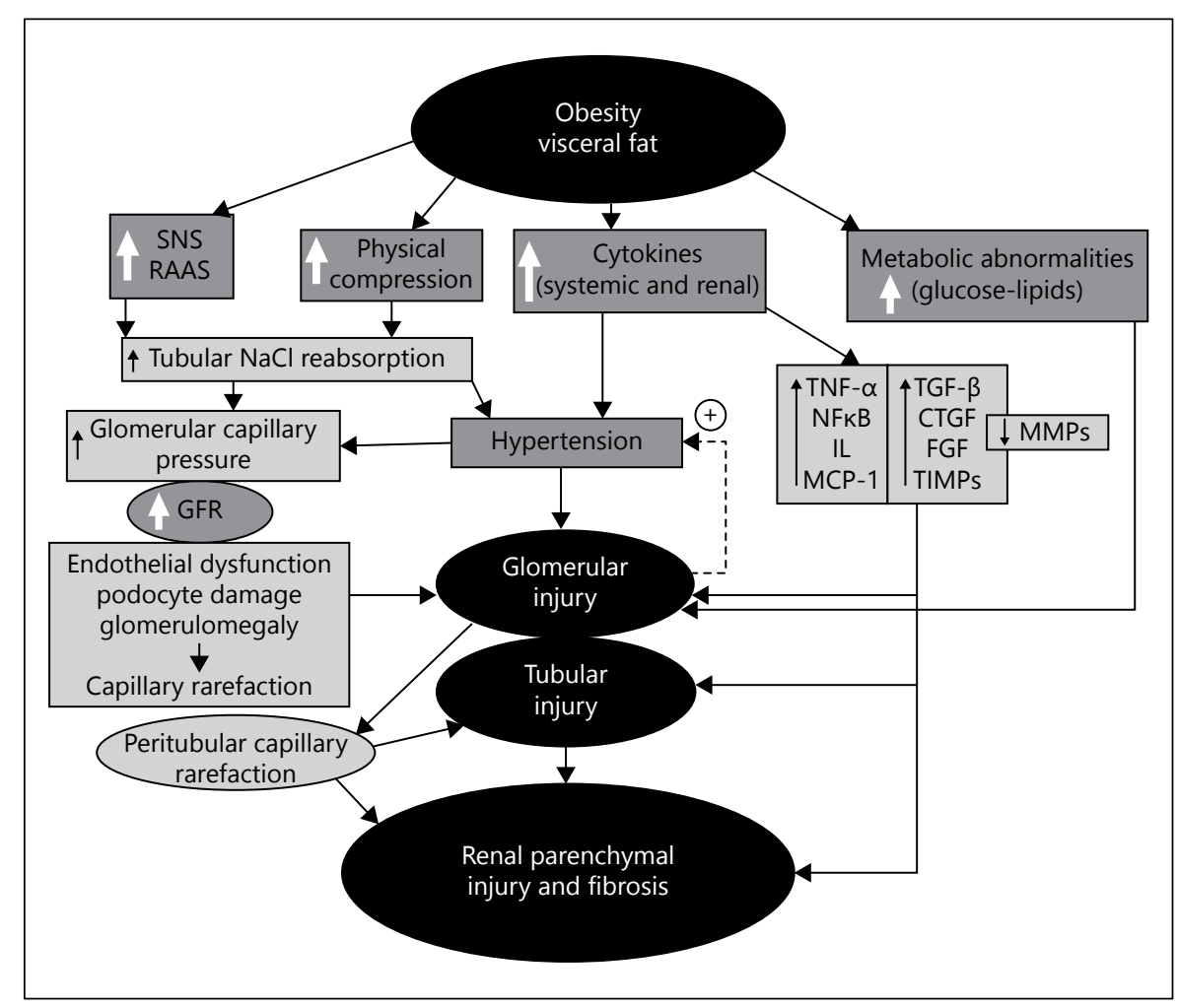

ology, and is an important feature of kidney injury in obesity. As discussed previously, the kidneys of obese subjects are chronically exposed to an injurious milieu due to adipose tissue-derived inflammatory and fibrotic-promoting cytokines, hypertension and various metabolic abnormalities [88]. Chronic inflammation can lead and accelerate nephron injury and renal fibrosis initiated by multiple co-existent insults, including hemodynamic and metabolic abnormalities associated with obesity.

The dysfunction, damage, remodeling and eventual loss of the renal microvessels has been described in advanced stages of hypertension, diabetes, and atherosclerotic renovascular disease, all of them being conditions promoted by obesity. Dysfunction and damage of the small renal vessels negatively impacts perfusion, leading to tissue ischemia and activation of hypoxia-derived and redox-sensitive factors in the kidney such as transforming growth factor- $\beta$ [89], connective tissue growth factor $[90,91]$ and fibroblast growth factor $[92,93]$, to name a few. In turn, some of these pro-fibrotic cytokines exert powerful effects on vascular proliferation and remodeling in addition to promoting epithelial and/or endothelialto-mesenchymal differentiation and fibrosis [94].

An ischemic and oxidative renal environment may also chronically interfere with normal ECM turnover by blunting activity of matrix metalloproteinases (MMPs) [95] or by increasing the resistance of ECM to degradation $[96,97]$ and by increasing specific tissue inhibitors of MMPs [98, 99]. Therefore, a pro-fibrotic activity paired with reduced ECM turnover could lead to buildup of fibrotic tissue and interfere with normal development, expansion and repair of the renal microvasculature. Furthermore, ECM accumulation may also affect renal microvessels by remodeling of the cortical and medullary vascular tree. Moreover, the ECM is an active source of inflammatory, pro- and anti-angiogenic cytokines $[100,101]$, which may further contribute to progression of renal MV abnormalities and parenchymal damage.

These potential mechanisms may also occur in kidneys exposed to obesity-associated diabetes and hypertension and contribute to progressive fibrosis. When hypertension and diabetes coexist, as occurs in many obese patients, it is likely that there are synergistic interactions that more rapidly promote kidney injury. The added physical compression of the kidneys by visceral and perinephric fat (discussed earlier) may exacerbate fibrosis and MV damage, contributing to a 'perfect storm' for progressive MV damage in the kidney exposed to obesity (fig. 2). 


\section{Dysfunction as Potential Instigator of Renal Injury in Obesity}

It is widely recognized that obesity induces changes in the function and structure of capillaries, conductance and resistance vessels in virtually every tissue or organ and that these changes may promote organ injury. Small vessel disease as an initial instigator of renal injury in obesity and as a risk factor for CKD is recognized, and can exacerbate injurious pathways that further advance tissue injury. However, it is challenging to isolate pathological contributions to renal MV dysfunction and damage to injury from other cardiovascular risk factors since MV abnormalities may develop in association with hypertension and diabetes, both independent of and in the context of obesity, and may promote or exacerbate renal injury via similar pathological pathways.

\section{Renal MV Dysfunction and Loss and Development of Renal Injury}

The role of MV rarefaction in initiating renal injury has been shown in different settings. For example, significant renal injury may develop after anti-angiogenic therapies in cancer. Inhibition of VEGF, a pivotal angiogenic cytokine that plays crucial roles in the generation of new vessels, repair and maintenance of the MV networks throughout the body, is a powerful anti-cancer intervention against the development and expansion of tumors. However, anti-VEGF therapies are also associated with significant renal MV injury, glomerulopathy and hypertension, all of which cause severe collateral damage of anti-angiogenic strategies that have been shown to develop with a clear cause-effect relationship [102, 103].

Disruption of the renal microcirculation may participate in development and progression of obesity-induced renal damage through several avenues. Glomerular hyperfiltration is a common finding in obese persons, driven by a combination of high sympathetic activity, activation of the renin-angiotensin system and hyperinsulinemia $[104,105]$. Paralleled by enhanced proximal or loop of Henle sodium reabsorption and a reduced delivery of sodium to the macula densa, a significant vasodilatation of the afferent arteriole develops and consequently, stimulation of renin synthesis [35]. The increase in angiotensin II induces constriction of the efferent arteriole, and the combination of afferent vasodilatation-efferent vasoconstriction leads to the hyperfiltration frequently observed in obese patients. This prolonged state of an abnormally transmitted arterial pressure to the glomerular capillaries may result in podocyte damage, glomerular enlargement, later capillary rarefaction and focal glomerulosclerosis and subsequent loss of glomeruli [105-107]. In turn, glomerular efferent vasoconstriction contributes to increased intraglomerular pressure and, in combination with other metabolic and inflammatory insults, ultimately to glomerular capillary injury and nephron loss. With loss of glomerular capillary function, there is reduced downstream peritubular capillary blood flow leading to ischemia and injury of the renal tubules and parenchyma $[20,108,109]$ (fig. 2).

Provocative evidence indicates that MV abnormalities may also contribute to the development of hypertension and metabolic derangements observed in obesity. MV rarefaction (functional and/or structural) may condition not only tissue vascular density, but also the maturity of the network structure and resistance to flow $[110,111]$. In the kidney, such mechanisms may result in loss of glomerular and peritubular capillaries, ultimately leading to renal tubular and generalized parenchymal injury associated with reductions in renal blood flow and GFR. These hemodynamic changes may contribute to further development of hypertension, further rarefaction and a gradual loss in kidney function.

Although renal mechanisms such as pressure natriuresis may compensate for increases in blood pressure associated with increased peripheral vascular resistance in other tissues, ongoing MV disease in the obese kidney with a reduction in the number of nephrons [18-20,112] may impair kidney function further, initiating a vicious circle that exacerbates the high blood pressure and vessel rarefaction in obesity $[113,114]$ (fig. 2 ).

\section{Does MV Dysfunction Promote Metabolic Disorders That Contribute to Renal Injury?}

Another potential consequence of MV disease in tissues such as skeletal muscle is its potential contribution to development of the obesity-induced metabolic derangements. Indeed, some investigators have suggested a potential role for abnormalities in the microcirculation to the development of metabolic defects often observed in obesity $[115,116]$ although others have provided evidence that does not support this hypothesis [117]. A major pathological feature in obese patients is insulin resistance, which may evolve into type 2 diabetes in patients who also have pancreatic $\beta$-cell dysfunction. Insulin resistance in skeletal muscle and liver seems to be partly driven by increased visceral adiposity that leads to a proinflammatory and pro-oxidative milieu and has been suggested to be closely related to MV dysfunction and remodeling [118]. 
Some studies suggest that MV dysfunction precedes metabolic insulin resistance, underscoring early deleterious events in the microcirculation that seem to be driven by inflammation $[119,120]$. Insulin is a vasodilator, due in part to its metabolic effects, and may redirect blood flow to increase perfusion through capillary networks, consequently stimulating insulin-mediated glucose uptake. This is partly an endothelium-dependent process that is impaired in states of MV dysfunction such as obesity [121] and may also have implications for the renal MV network [118]. Although transport across the cell membrane, rather than the capillaries, is generally the rate limiting step for glucose uptake in skeletal muscle $[117,122]$, severe MV dysfunction may impair glucose and insulin delivery, and exacerbate impaired glucose uptake and utilization by peripheral tissues [123].

Increases in vascular permeability associated with the inflammatory milieu of obesity [85] may facilitate mobilization of injurious substances to the extravascular tissues in type 2 diabetes, commonly associated with obesity. Abundance of inflammatory cytokines and glucose may further increase vascular permeability [124], increase oxidative stress, promote vasoconstriction [125], stimulate pro-fibrotic activity and deteriorate glucose trafficking leading to endothelial cell death by interfering with mitochondrial function [126], which in turn may further increase vascular and perivascular damage in the kidney.

\section{Potential Therapeutic Strategies: Protection of Renal Microvessels}

Targeting the renal microcirculation as a potential therapeutic strategy for obesity-induced kidney injury has not been widely explored. Although the first therapeutic steps should focus on weight management and control of obesity-driven cardiovascular and metabolic derangements, protection of the microcirculation may be an additional strategy for renoprotection.

\section{Weight Loss}

Weight loss via caloric restriction and increased physical activity are core therapies for obese individuals that can improve most of the metabolic, cardiovascular and renal derangements associated with obesity such as hypertension, glucose control, proteinuria and renal function. The inclusion of bariatric surgery as a strategy for weight loss has provided additional benefits. Indeed, bariatric surgery seems to be more effective for weight loss and has a long-term benefit on improving weight control, metabolic derangements, recovery of renal function and halting the cascade of events that cause progression of renal damage [127-129].

Weight loss by lifestyle modifications (diet, exercise) or bariatric interventions in obese patients may attenuate endothelial dysfunction, reduce cardiovascular risk and improve prognosis in the obese population [130]. Part of the improvement in endothelial function and overall MV protection by weight loss may be driven by improvements in leptin signaling (with subsequent vascular recovery [131]), restoration of circulating endothelial progenitor cells (reduced in obese patients), enhanced endogenous mechanisms of vascular and tissue repair, and decreased MV remodeling and perivascular fibrosis [132]. Weight loss also reduces production and release of cytokines responsible for the chronic pro-inflammatory and pro-fibrotic state observed in visceral obesity. Other major effects of weight loss include reductions in blood pressure, regression and diabetes and improvements in dyslipidemia, as have been recently reviewed $[16,133,134]$.

\section{Anti-Diabetic Drugs}

Obesity, hypertension and poor glycemic control can lead to cardiovascular complications associated with endothelial dysfunction, vascular hypertrophy and remodeling of large blood vessels, resistance arteries and the microcirculation [135, 136]. Metformin and insulin administration are mainstream therapies in diabetes and have been shown to improve MV endothelial function directly and via improved glycemic control. Mechanisms of vascular protection by metformin include reducing endothelial cell senescence and apoptosis, attenuating hyperglycemia-induced oxidative stress [137] and promoting angiogenesis via AMP-k/eNOS pathways [138]. Similarly, insulin has a vasodilatory effect that is counteracted by chronic hyperglycemia [139] and resistance to insulin associates with MV endothelial damage driven by increased susceptibility to ischemia and loss of pro-survival effects. Weight loss and improved glucose control by some antidiabetic drugs such as GLP-1 agonists and SGLT-2 inhibitors may at least partially correct the impaired vasodilation response to various stimuli, such as exercise, and endothelial damage which increases susceptibility to ischemia. Although most of the beneficial effects of antidiabetic drugs and enhanced glycemic control have been described for skeletal muscle, retina or isolated endothelial cells, these drugs might also ameliorate renal MV rarefaction and slow the progression of renal injury [140, 141]. 


\section{Anti-Hypertensive and Lipid-Lowering Drugs}

Obesity carries a high risk for development of hypertension and lipid abnormalities. Consequently, a large number of obese patients receive treatment with anti-hypertensive and lipid-lowering drugs that may also have beneficial pleiotropic effects on the vasculature. Angiotensin converting enzyme (ACE) inhibitors and angiotensin receptor blockers (ARBs) are among the first line of anti-hypertensive medications. Considerable evidence indicates that the blood pressure lowering effect is the major driving force behind most of their protective effects on the cardiovascular subsystems and the kidneys [142]. However, some evidence that comes mainly from studies in experimental obesity show additional benefits of ACE/ ARBs by reducing renal damage and, possibly via PPAR- $\gamma$ mediated effects, improving insulin sensitivity, restoring vascular function and perhaps even contributing to fat redistribution away from visceral depots in some cases [143-145].

Obesity-induced dyslipidemia is counteracted by dietary interventions and lipid-lowering drugs such as HMG-CoA reductase inhibitors (statins). Beyond lipid lowering, the pleiotropic effects of statins have been described elsewhere $[146,147]$ and have also been suggested to have beneficial effects in the microcirculation of various tissues, including the kidneys. Indeed, based on their powerful anti-oxidant and NO-mediated vasoactive effects, statins may exert direct protective effects on vascular endothelial function. We showed that hypercholesterolemia and atherosclerotic renovascular disease cause blunted cardiac and renal hemodynamics and function that are associated with significant MV endothelial dysfunction and rarefaction, which are restored after chronic simvastatin therapy, independent of any lipid-lowering effect [94, 148-150]. Thus, protection of MV function and structure could be considered as an additional mechanism of renoprotection by anti-hypertensive and lipid-lowering strategies in obesity.

\section{Potential Novel Therapies}

In addition to VEGF, other factors that are produced by adipose-derived stem cells may induce or attenuate angiogenesis. For example, a novel factor that may serve as a powerful instigator of aberrant angiogenesis is the glialderived neurotrophic factor (GDNF). A recent study shows that GDNF promotes pathological neovascularization by stimulating endothelial cell network formation in a VEGF-independent fashion, implying GDNF may be a target for obesity-induced organ damage [62].
Another important pro-angiogenic factor that is produced by and acts on adipose tissue and adipose-derived stem cells is the hepatocyte growth factor [151]. This factor may promote neovascularization both directly and via synergism with VEGF and has also been shown to induce protective actions on the vasculature, possibly via attenuation of pro-fibrotic and remodeling pathways $[152,153]$ and promoting cell mobilization and tissue repair [154].

Since the growth of adipose tissue is paralleled by vascular proliferation, as it occurs in other organs, modulation of angiogenesis may be an adjuvant intervention to reduce target organ injury. Inhibition of angiogenesis as an intervention to prevent accumulation of adipose tissue or its consequences (directly or as co-adjuvant strategy) has been attempted in experimental settings [155]. However, anti-angiogenic strategies may elicit important collateral effects such as renal injury and hypertension, which clearly limit their potential for therapeutic applications.

\section{Conclusions and Perspectives}

The epidemic growth of obesity has been the impetus for numerous experimental and clinical studies to determine the pathological consequences and mechanisms of widespread organ injury associated with higher all-cause mortality in obese patients $[156,157]$. Current efforts on early dietary education, weight control, active lifestyle and interventions are abundant but have been largely ineffective in slowing the increasing prevalence of obesity. Until more effective therapies for obesity are available, research should also focus on ameliorating target organ injury.

Obese patients are at higher risk of developing CKD. Current therapies and interventions may improve, but do not halt, the progression of renal MV dysfunction and associated cardiovascular risk. Thus, major efforts are needed to understand the pathophysiological mechanisms leading to progressive renal dysfunction and damage. In the kidney, functional and structural injury to the microvasculature is increasingly recognized as a prominent instigator of renal parenchymal injury. However, kidney-targeted stimulation of MV function, neovascularization and inhibition of vascular remodeling are still experimental as therapeutic strategies and warrant additional studies. Pro-angiogenic therapies that stimulate regrowth of glomerular and peritubular capillaries appear promising in experimental studies but there are still chal- 
lenges that prevent this approach from being practical in a clinical setting, such as short half-life and rapid degradation of administered pro-angiogenic peptides. Also, specific targeting of the kidney microvasculature will be needed to avoid potential deleterious effects in other organs that could occur with widespread increases in angiogenesis.

Additional research is also needed to define the potential contribution of systemic MV dysfunction to the development of metabolic derangements in obesity, whether these mechanisms are mirrored in the kidney and if they are important therapeutic targets. Elucidation of such mechanisms of renal MV damage in obesity may not only help to understand these complex processes, but may also lead to new strategies in treating the adverse metabolic, cardiovascular and renal consequences of obesity.

\section{Acknowledgments}

This work was supported by grant HL095638, PO1-HL51971, P20-GM104357 and U54-GM115428 from the National Institutes of Health, and by grant 18490005 from the American Heart Association.

\section{Disclosure Statement}

The authors have no conflicts of interest to declare.

\section{References}

1 Ogden CL, Carroll MD, Kit BK, Flegal KM: Prevalence of obesity among adults: United States, 2011-2012. NCHS Data Brief 2013; 131:1-8.

2 Flegal KM, Kruszon-Moran D, Carroll MD, Fryar CD, Ogden CL: Trends in obesity among adults in the United States, 2005 to 2014. JAMA 2016;315:2284-2291.

3 Center for Disease Control and Prevention: Childhood Obesity Facts. 2016. http://www. cdc.gov/obesity/data/childhood.html.

4 National Institute of Diabetic and Digestive and Kidney Diseases-National Institutes of Health. Overweight and Obesity Statistics. 2016. http:// www.niddk.nih.gov/health-information/ health-statistics/Pages/overweight-obesitystatistics.aspx.

5 World Health Organization: Obesity and Overweight, 2016.

6 US Renal Data System and Annual Data Report: Atlas of Chronic Kidney Disease and End-Stage Renal Disease in the United States. Bethesda, National Institutes of Health, $\mathrm{Na}$ tional Institute of Diabetes and Digestive and Kidney Diseases, 2015.

7 Foster MC, Hwang SJ, Larson MG, Lichtman JH, Parikh NI, Vasan RS, Levy D, Fox CS: Overweight, obesity, and the development of stage 3 CKD: the Framingham Heart Study. Am J Kidney Dis 2008;52:39-48.

8 Cao X, Zhou J, Yuan H, Wu L, Chen Z: Chronic kidney disease among overweight and obesity with and without metabolic syndrome in an urban Chinese cohort. BMC Nephrol 2015;16:85.

9 Gabbay E, Slotki I, Shavit L: Weighing the evidence: obesity, metabolic syndrome, and the risk of chronic kidney disease. BMC Nephrol 2015; 16:133.

10 Wickman C, Kramer H: Obesity and kidney disease: potential mechanisms. Semin Nephrol 2013;33:14-22.
11 Tanaka M, Yamada S, Iwasaki Y, Sugishita T, Yonemoto S, Tsukamoto T, Fukui S, Takasu $\mathrm{K}$, Muso E: Impact of obesity on IgA nephropathy: comparative ultrastructural study between obese and non-obese patients. Nephron Clin Pract 2009;112:c71-c78.

12 van der Heijden RA, Bijzet J, Meijers WC, Yakala GK, Kleemann R, Nguyen TQ, de Boer RA, Schalkwijk CG, Hazenberg BP, Tietge UJ, Heeringa P: Obesity-induced chronic inflammation in high fat diet challenged C57BL/6J mice is associated with acceleration of age-dependent renal amyloidosis. Sci Rep 2015;5:16474.

13 Hsu CY, McCulloch CE, Iribarren C, Darbinian J, Go AS: Body mass index and risk for end-stage renal disease. Ann Intern Med 2006;144:21-28.

14 Kramer H, Shoham D, McClure LA, DurazoArvizu R, Howard G, Judd S, Muntner P, Safford M, Warnock DG, McClellan W: Association of waist circumference and body mass index with all-cause mortality in CKD: the REGARDS (Reasons for Geographic and Racial Differences in Stroke) Study. Am J Kidney Dis 2011;58:177-185.

15 Foster MC, Hwang SJ, Porter SA, Massaro JM, Hoffmann U, Fox CS: Fatty kidney, hypertension, and chronic kidney disease: the Framingham Heart Study. Hypertension 2011;58:784790.

16 Hall ME, do Carmo JM, da Silva AA, Juncos LA, Wang Z, Hall JE: Obesity, hypertension, and chronic kidney disease. Int J Nephrol Renovasc Dis 2014;7:75-88.

17 Kazancioğlu R: Risk factors for chronic kidney disease: an update. Kidney Int Suppl (2011) 2013;3:368-371.

18 Gurusinghe S, Brown RD, Cai X, Samuel CS, Ricardo SD, Thomas MC, Kett MM: Does a nephron deficit exacerbate the renal and cardiovascular effects of obesity? PLoS One 2013; 8:e73095.
19 Praga M: Synergy of low nephron number and obesity: a new focus on hyperfiltration nephropathy. Nephrol Dial Transplant 2005; 20:2594-2597.

20 Tsuboi N, Utsunomiya Y, Hosoya T: Obesityrelated glomerulopathy and the nephron complement. Nephrol Dial Transplant 2013; 28(suppl 4):iv108-iv113.

21 Iliescu R, Chade AR: Progressive renal vascular proliferation and injury in obese Zucker rats. Microcirculation 2010;17:250-258.

22 Kelly AS, Ryder JR, Marlatt KL, Rudser KD, Jenkins $\mathrm{T}$, Inge $\mathrm{TH}$ : Changes in inflammation, oxidative stress and adipokines following bariatric surgery among adolescents with severe obesity. Int J Obes (Lond) 2016;40: 275-280.

23 Tang J, Yan H, Zhuang S: Inflammation and oxidative stress in obesity-related glomerulopathy. Int J Nephrol 2012;2012:608397.

24 Chade AR, Bentley MD, Zhu X, RodriguezPorcel M, Niemeyer S, Amores-Arriaga B, Napoli C, Ritman EL, Lerman A, Lerman LO: Antioxidant intervention prevents renal neovascularization in hypercholesterolemic pigs. J Am Soc Nephrol 2004; 15:18161825.

25 Maric-Bilkan C, Flynn ER, Chade AR: Microvascular disease precedes the decline in renal function in the streptozotocin-induced diabetic rat. Am J Physiol Renal Physiol 2012; 302:F308-F315.

26 Zhu XY, Chade AR, Rodriguez-Porcel M, Bentley MD, Ritman EL, Lerman A, Lerman LO: Cortical microvascular remodeling in the stenotic kidney: role of increased oxidative stress. Arterioscler Thromb Vasc Biol 2004; 24:1854-1859.

27 Rieder MJ, Roman RJ, Greene AS: Reversal of microvascular rarefaction and reduced renal mass hypertension. Hypertension 1997; 30(1 pt 1):120-127. 
28 Martens RJ, Henry RM, Houben AJ, van der Kallen CJ, Kroon AA, Schalkwijk CG, Schram MT, Sep SJ, Schaper NC, Dagnelie PC, Muris DM, Gronenschild EH, van der Sande FM, Leunissen KM, Kooman JP, Stehouwer CD: Capillary rarefaction associates with albuminuria: the Maastricht study. J Am Soc Nephrol 2016;pii:ASN.2015111219.

29 Anderson S, Halter JB, Hazzard WR, Himmelfarb J, Horne FM, Kaysen GA, Kusek JW, Nayfield SG, Schmader K, Tian Y, Ashworth JR, Clayton CP, Parker RP, Tarver ED, Woolard NF, High KP; Workshop Participants: Prediction, progression, and outcomes of chronic kidney disease in older adults. J Am Soc Nephrol 2009;20:1199-1209.

30 de Vries AP, Ruggenenti P, Ruan XZ, Praga M, Cruzado JM, Bajema IM, D’Agati VD, Lamb HJ, Pongrac Barlovic D, Hojs R, Abbate $M$, Rodriquez R, Mogensen CE, Porrini E; ERA-EDTA Working Group Diabesity: Fatty kidney: emerging role of ectopic lipid in obesity-related renal disease. Lancet Diabetes Endocrinol 2014;2:417-426.

31 de Jongh RT, Serné EH, IJzerman RG, de Vries G, Stehouwer CD: Impaired microvascular function in obesity: implications for obesity-associated microangiopathy, hypertension, and insulin resistance. Circulation 2004;109:2529-2535.

32 de Jongh RT, Serné EH, IJzerman RG, Jørstad HT, Stehouwer CD: Impaired local microvascular vasodilatory effects of insulin and reduced skin microvascular vasomotion in obese women. Microvasc Res 2008;75:256-262.

33 Khan F, Green FC, Forsyth JS, Greene SA, Morris AD, Belch JJ: Impaired microvascular function in normal children: effects of adiposity and poor glucose handling. J Physiol 2003; 551(pt 2):705-711.

34 Kramer H: Obesity and chronic kidney disease. Contrib Nephrol 2006;151:1-18.

35 Hall JE, do Carmo JM, da Silva AA, Wang Z, Hall ME: Obesity-induced hypertension: interaction of neurohumoral and renal mechanisms. Circ Res 2015;116:991-1006.

36 Hall JE, Brands MW, Henegar JR, Shek EW: Abnormal kidney function as a cause and a consequence of obesity hypertension. Clin Exp Pharmacol Physiol 1998;25:58-64.

37 Ferrante AW Jr: The immune cells in adipose tissue. Diabetes Obes Metab 2013;15(suppl 3):34-38.

38 Huh JY, Park YJ, Ham M, Kim JB: Crosstalk between adipocytes and immune cells in adipose tissue inflammation and metabolic dysregulation in obesity. Mol Cells 2014;37:365371.

39 Mraz M, Haluzik M: The role of adipose tissue immune cells in obesity and low-grade inflammation. J Endocrinol 2014;222:R113R127.

40 Chmelar J, Chung KJ, Chavakis T: The role of innate immune cells in obese adipose tissue inflammation and development of insulin resistance. Thromb Haemost 2013;109:399406.
41 Oishi Y, Manabe I: Integrated regulation of the cellular metabolism and function of immune cells in adipose tissue. Clin Exp Pharmacol Physiol 2016;43:294-303.

42 Eirin A, Zhu XY, Ebrahimi B, Krier JD, Riester SM, van Wijnen AJ, Lerman A, Lerman LO: Intrarenal delivery of mesenchymal stem cells and endothelial progenitor cells attenuates hypertensive cardiomyopathy in experimental renovascular hypertension. Cell Transplant 2015;24:2041-2053.

43 Eirin A, Zhu XY, Ferguson CM, Riester SM, van Wijnen AJ, Lerman A, Lerman LO: Intrarenal delivery of mesenchymal stem cells attenuates myocardial injury after reversal of hypertension in porcine renovascular disease. Stem Cell Res Ther 2015;6:7.

44 Eirin A, Zhu XY, Krier JD, Tang H, Jordan KL, Grande JP, Lerman A, Textor SC, Lerman LO: Adipose tissue-derived mesenchymal stem cells improve revascularization outcomes to restore renal function in swine atherosclerotic renal artery stenosis. Stem Cells 2012;30:1030-1041.

45 Zhu XY, Urbieta-Caceres V, Krier JD, Textor SC, Lerman A, Lerman LO: Mesenchymal stem cells and endothelial progenitor cells decrease renal injury in experimental swine renal artery stenosis through different mechanisms. Stem Cells 2013;31:117-125.

46 Carraro A, Buggio M, Gardin C, Tedeschi U, Ferroni L, Zavan PB: Mesenchymal stem cells increase neo-angiogenesis and albumin production in a liver tissue-engineered engraftment. Int J Mol Sci 2016;17:374.

47 Huang B, Cheng X, Wang H, Huang W, la Ga Hu Z, Wang D, Zhang K, Zhang H, Xue Z, Da Y, Zhang N, Hu Y, Yao Z, Qiao L, Gao F, Zhang R: Mesenchymal stem cells and their secreted molecules predominantly ameliorate fulminant hepatic failure and chronic liver fibrosis in mice respectively. J Transl Med 2016; 14:45.

48 He QQ, He X, Wang YP, Zou Y, Xia QJ, Xiong LL, Luo CZ, Hu XS, Liu J, Wang TH: Transplantation of bone marrow-derived mesenchymal stem cells (BMSCs) improves brain ischemia-induced pulmonary injury in rats associated to TNF- $\alpha$ expression. Behav Brain Funct 2016;12:9.

49 Mangraviti A, Tzeng SY, Gullotti D, Kozielski KL, Kim JE, Seng M, Abbadi S, Schiapparelli P, Sarabia-Estrada R, Vescovi A, Brem H, Olivi A, Tyler B, Green JJ, Quinones-Hinojosa A: Non-virally engineered human adipose mesenchymal stem cells produce BMP4, target brain tumors, and extend survival. Biomaterials 2016;100:53-66.

50 Strioga M, Viswanathan S, Darinskas A, Slaby O, Michalek J: Same or not the same? Comparison of adipose tissue-derived versus bone marrow-derived mesenchymal stem and stromal cells. Stem Cells Dev 2012;21:2724-2752.

51 Wang M, Crisostomo PR, Herring C, Meldrum KK, Meldrum DR: Human progenitor cells from bone marrow or adipose tissue produce VEGF, HGF, and IGF-I in response to
TNF by a p38 MAPK-dependent mechanism. Am J Physiol Regul Integr Comp Physiol 2006;291:R880-R884.

52 During MJ, Liu X, Huang W, Magee D, Slater A, McMurphy T, Wang C, Cao L: Adipose VEGF Links the white-to-brown fat switch with environmental, genetic, and pharmacological stimuli in male mice. Endocrinology 2015;156:2059-2073.

53 Jo DH, Park SW, Cho CS, Powner MB, Kim $\mathrm{JH}$, Fruttiger $\mathrm{M}, \mathrm{Kim} \mathrm{JH}$ : Intravitreally injected anti-VEGF antibody reduces brown fat in neonatal mice. PLoS One 2015;10:e0134308.

54 Elias I, Franckhauser S, Bosch F: New insights into adipose tissue VEGF-A actions in the control of obesity and insulin resistance. Adipocyte 2013;2:109-112.

55 Hagberg CE, Mehlem A, Falkevall A, Muhl L, Fam BC, Ortsäter H, Scotney P, Nyqvist D, Samén E, Lu L, Stone-Elander S, Proietto J, Andrikopoulos S, Sjöholm A, Nash A, Eriksson U: Targeting VEGF-B as a novel treatment for insulin resistance and type 2 diabetes. Nature 2012;490:426-430.

56 Ngo DT, Farb MG, Kikuchi R, Karki S, Tiwari S, Bigornia SJ, Bates DO, LaValley MP, Hamburg NM, Vita JA, Hess DT, Walsh K, Gokce $\mathrm{N}$ : Antiangiogenic actions of vascular endothelial growth factor-A165b, an inhibitory isoform of vascular endothelial growth factorA, in human obesity. Circulation 2014;130: 1072-1080.

57 Hamdy O, Porramatikul S, Al-Ozairi E: Metabolic obesity: the paradox between visceral and subcutaneous fat. Curr Diabetes Rev 2006;2:367-373.

58 Kaess BM, Pedley A, Massaro JM, Murabito J, Hoffmann U, Fox CS: The ratio of visceral to subcutaneous fat, a metric of body fat distribution, is a unique correlate of cardiometabolic risk. Diabetologia 2012;55:2622-2630.

59 Kang SH, Cho KH, Park JW, Yoon KW, Do JY: Association of visceral fat area with chronic kidney disease and metabolic syndrome risk in the general population: analysis using multi-frequency bioimpedance. Kidney Blood Press Res 2015;40:223-230.

60 Bruno S, Bussolati B, Grange C, Collino F, di Cantogno LV, Herrera MB, Biancone L, Tetta C, Segoloni G, Camussi G: Isolation and characterization of resident mesenchymal stem cells in human glomeruli. Stem Cells Dev 2009; 18:867-880.

61 Reule S, Gupta S: Kidney regeneration and resident stem cells. Organogenesis 2011;7: 135-139.

62 Zhong Z, Gu H, Peng J, Wang W, Johnstone BH, March KL, Farlow MR, Du Y: GDNF secreted from adipose-derived stem cells stimulates VEGF-independent angiogenesis. Oncotarget 2016;7:36829-36841.

63 Liu L, Gao J, Yuan Y, Chang Q, Liao Y, Lu F: Hypoxia preconditioned human adipose derived mesenchymal stem cells enhance angiogenic potential via secretion of increased VEGF and bFGF. Cell Biol Int 2013;37:551560 . 
64 Matsugami H, Harada Y, Kurata Y, Yamamoto $Y$, Otsuki Y, Yaura H, Inoue Y, Morikawa K, Yoshida A, Shirayoshi Y, Suyama Y, Nakayama B, Iwaguro $H$, Yamamoto $K$, Hisatome I: VEGF secretion by adipose tissue-derived regenerative cells is impaired under hyperglycemic conditions via glucose transporter activation and ROS increase. Biomed Res 2014;35:397-405.

65 Qian Y, Zhang Y, Zhong P, Peng K, Xu Z, Chen X, Lu K, Chen G, Li X, Liang G: Inhibition of inflammation and oxidative stress by an imidazopyridine derivative X22 prevents heart injury from obesity. J Cell Mol Med 2016;20:1427-1442.

66 Wang HT, Liu CF, Tsai TH, Chen YL, Chang HW, Tsai CY, Leu S, Zhen YY, Chai HT, Chung SY, Chua S, Yen CH, Yip HK: Effect of obesity reduction on preservation of heart function and attenuation of left ventricular remodeling, oxidative stress and inflammation in obese mice. J Transl Med 2012;10:145.

67 Park EJ,Lee JH, Yu GY, He G, Ali SR, Holzer RG, Osterreicher $\mathrm{CH}$, Takahashi H, Karin M: Dietary and genetic obesity promote liver inflammation and tumorigenesis by enhancing IL- 6 and TNF expression. Cell 2010;140:197-208.

68 Bailey-Downs LC, Tucsek Z, Toth P, Sosnowska D, Gautam T, Sonntag WE, Csiszar A, Ungvari Z: Aging exacerbates obesity-induced oxidative stress and inflammation in perivascular adipose tissue in mice: a paracrine mechanism contributing to vascular redox dysregulation and inflammation. J Gerontol A Biol Sci Med Sci 2013;68:780-792.

69 Van de Voorde J, Boydens C, Pauwels B, Decaluwe K: Perivascular adipose tissue, inflammation and vascular dysfunction in obesity. Curr Vasc Pharmacol 2014;12:403-411.

70 Lumeng CN, Saltiel AR: Inflammatory links between obesity and metabolic disease. J Clin Invest 2011;121:2111-2117.

71 Navarro-Díaz M, Serra A, López D, Granada M, Bayés B, Romero R: Obesity, inflammation, and kidney disease. Kidney Int Suppl 2008;111:S15-S18.

72 Skinner AC, Steiner MJ, Henderson FW, Perrin EM: Multiple markers of inflammation and weight status: cross-sectional analyses throughout childhood. Pediatrics 2010;125: e801-e809.

73 Costa C, Incio J, Soares R: Angiogenesis and chronic inflammation: cause or consequence? Angiogenesis 2007;10:149-166.

74 Hammam O, Mahmoud O, Zahran M, Sayed A, Salama R, Hosny K, Farghly A: A possible role for TNF- $\alpha$ in coordinating inflammation and angiogenesis in chronic liver disease and hepatocellular carcinoma. Gastrointest Cancer Res 2013;6:107-114.

75 Liu Y, Yang G, Zhang J, Xing K, Dai L, Cheng L, Liu J, Deng J, Shi G, Li C, Su X, Zhang S, Yang Y, Li J, Yu D, Xiang R, Wei Y, Deng H: Anti-TNF- $\alpha$ monoclonal antibody reverses psoriasis through dual inhibition of inflammation and angiogenesis. Int Immunopharmacol 2015;28:731-743.
76 Chen L, Marble DJ, Agha R, Peterson JD, Becker RP, Jin T, Li J, Chan LS: The progression of inflammation parallels the dermal angiogenesis in a keratin 14 IL-4-transgenic model of atopic dermatitis. Microcirculation 2008;15:49-64.

77 O’Neill L, Rooney P, Molloy D, Connolly M, McCormick J, McCarthy G, Veale DJ, Murphy CC, Fearon U, Molloy E: Regulation of inflammation and angiogenesis in giant cell arteritis by acute-phase serum amyloid A. Arthritis Rheumatol 2015;67:2447-2456.

78 Wang C, Duan H, He L: Inhibitory effect of atractylenolide I on angiogenesis in chronic inflammation in vivo and in vitro. Eur J Pharmacol 2009;612:143-152.

79 Aplin AC, Fogel E, Nicosia RF: MCP-1 promotes mural cell recruitment during angiogenesis in the aortic ring model. Angiogenesis 2010;13:219-226.

80 Kanda H, Tateya S, Tamori Y, Kotani K, Hiasa K, Kitazawa R, Kitazawa S, Miyachi H, Maeda S, Egashira K, Kasuga M: MCP-1 contributes to macrophage infiltration into adipose tissue, insulin resistance, and hepatic steatosis in obesity. J Clin Invest 2006;116:14941505.

81 Kim CS, Park HS, Kawada T, Kim JH, Lim D, Hubbard NE, Kwon BS, Erickson KL, Yu R: Circulating levels of MCP-1 and IL- 8 are elevated in human obese subjects and associated with obesity-related parameters. Int J Obes (Lond) 2006;30:1347-1355.

82 Ohman MK, Eitzman DT: Targeting MCP-1 to reduce vascular complications of obesity. Recent Pat Cardiovasc Drug Discov 2009; 164-176.

83 Panee J: Monocyte chemoattractant protein 1 (MCP-1) in obesity and diabetes. Cytokine 2012;60:1-12.

84 Quilley J: Oxidative stress and inflammation in the endothelial dysfunction of obesity: a role for nuclear factor kappa B? J Hypertens 2010;28:2010-2011.

85 Chade AR, Krier JD, Galili O, Lerman A, Lerman LO: Role of renal cortical neovascularization in experimental hypercholesterolemia. Hypertension 2007;50:729-736.

86 Carraway RE, Cochrane DE: Enhanced vascular permeability is hypothesized to promote inflammation-induced carcinogenesis and tumor development via extravasation of large molecular proteins into the tissue. Med Hypotheses 2012;78:738-743.

87 Chade AR, Krier JD, Textor SC, Lerman A, Lerman LO: Endothelin-a receptor blockade improves renal microvascular architecture and function in experimental hypercholesterolemia. J Am Soc Nephrol 2006;17:3394-3403.

88 Decleves AE, Sharma K: Obesity and kidney disease: differential effects of obesity on adipose tissue and kidney inflammation and fibrosis. Curr Opin Nephrol Hypertens 2015; 24:28-36.

89 Meng XM, Tang PM, Li J, Lan HY: TGF- $\beta$ / smad signaling in renal fibrosis. Front Physiol 2015;6:82.
90 Phanish MK, Winn SK, Dockrell ME: Connective tissue growth factor-(CTGF, CCN2) - a marker, mediator and therapeutic target for renal fibrosis. Nephron Exp Nephrol 2010;114:e83-e92.

91 Wang J, Duan L, Guo T, Gao Y, Tian L, Liu J, Wang S, Yang J: Downregulation of miR30c promotes renal fibrosis by target CTGF in diabetic nephropathy. J Diabetes Complications 2016;30:406-414.

92 Guan X, Nie L, He T, Yang K, Xiao T, Wang S, Huang Y, Zhang J, Wang J, Sharma K, Liu Y, Zhao J: Klotho suppresses renal tubulointerstitial fibrosis by controlling basic fibroblast growth factor-2 signalling. J Pathol 2014;234:560-572.

93 Morita H, Shinzato T, David G, Mizutani A Habuchi H, Fujita Y, Ito M, Asai J, Maeda K, Kimata K: Basic fibroblast growth factorbinding domain of heparan sulfate in the human glomerulosclerosis and renal tubulointerstitial fibrosis. Lab Invest 1994;71:528-535.

94 Chade AR, Zhu XY, Grande JP, Krier JD, Lerman A, Lerman LO: Simvastatin abates development of renal fibrosis in experimental renovascular disease. J Hypertens 2008;26: 1651-1660.

95 Ganguly K, Kundu P, Banerjee A, Reiter RJ, Swarnakar S: Hydrogen peroxide-mediated downregulation of matrix metalloprotease- 2 in indomethacin-induced acute gastric ulceration is blocked by melatonin and other antioxidants. Free Radic Biol Med 2006;41:911-925.

96 Mattana J, Margiloff L, Chaplia L: Oxidation of extracellular matrix modulates susceptibility to degradation by the mesangial matrix metalloproteinase-2. Free Radic Biol Med 1999;27:315-321.

97 Mattana J, Margiloff L, Sharma P, Singhal PC: Oxidation of the mesangial matrix metalloproteinase-2 impairs gelatinolytic activity. Inflammation 1998;22:269-276.

98 Yang ZZ, Zou AP: Homocysteine enhances TIMP-1 expression and cell proliferation associated with NADH oxidase in rat mesangial cells. Kidney Int 2003;63:1012-1020.

99 Norman JT, Clark IM, Garcia PL: Regulation of TIMP-1 expression by hypoxia in kidney fibroblasts. Ann N Y Acad Sci 1999;878:503505.

100 Edgar LT, Underwood CJ, Guilkey JE, Hoying JB, Weiss JA: Extracellular matrix density regulates the rate of neovessel growth and branching in sprouting angiogenesis. PLoS One 2014;9:e85178.

101 Neve A, Cantatore FP, Maruotti N, Corrado A, Ribatti D: Extracellular matrix modulates angiogenesis in physiological and pathological conditions. Biomed Res Int 2014;2014 756078.

102 Eremina V, Jefferson JA, Kowalewska J, Hochster H, Haas M, Weisstuch J, Richardson C, Kopp JB, Kabir MG, Backx PH, Gerber HP, Ferrara N, Barisoni L, Alpers CE, Quaggin SE: VEGF inhibition and renal thrombotic microangiopathy. N Engl J Med 2008;358:1129-1136. 
103 Eremina V, Quaggin SE: The role of VEGFA in glomerular development and function. Curr Opin Nephrol Hypertens 2004;13:915.

104 Knight SF, Imig JD: Obesity, insulin resistance, and renal function. Microcirculation 2007;14:349-362.

105 Zoccali C: Overweight, obesity and metabolic alterations in chronic kidney disease. Prilozi 2009;30:17-31.

106 Chagnac A, Weinstein T, Korzets A, Ramadan E, Hirsch J, Gafter U: Glomerular hemodynamics in severe obesity. Am J Physiol Renal Physiol 2000;278:F817-F822.

107 Valera Mora ME, Scarfone A, Calvani M, Greco AV, Mingrone G: Insulin clearance in obesity. J Am Coll Nutr 2003;22:487-493.

108 Griffin KA, Kramer H, Bidani AK: Adverse renal consequences of obesity. Am J Physiol Renal Physiol 2008;294:F685-F696.

109 Joles JA, Koomans HA: Causes and consequences of increased sympathetic activity in renal disease. Hypertension 2004;43:699706.

110 Jacobsen JC, Gustafsson F, Holstein-Rathlou NH: A model of physical factors in the structural adaptation of microvascular networks in normotension and hypertension. Physiol Meas 2003;24:891-912.

111 Jacobsen JC, Hornbech MS, Holstein-Rathlou NH: A tissue in the tissue: models of microvascular plasticity. Eur J Pharm Sci 2009; 36:51-61.

112 le Noble FA, Stassen FR, Hacking WJ, Struijker Boudier HA: Angiogenesis and hypertension. J Hypertens 1998;16:1563-1572.

113 Johnson RJ, Herrera-Acosta J, Schreiner GF, Rodriguez-Iturbe B: Subtle acquired renal injury as a mechanism of salt-sensitive hypertension. N Engl J Med 2002;346:913-923.

114 Johnson RJ, Rodriguez-Iturbe B, Schreiner GF, Herrera-Acosta J: Hypertension: a microvascular and tubulointerstitial disease. J Hypertens Suppl 2002;20:S1-S7.

115 Houben AJ, Eringa EC, Jonk AM, Serne EH, Smulders YM, Stehouwer CD: Perivascular fat and the microcirculation: relevance to insulin resistance, diabetes, and cardiovascular disease. Curr Cardiovasc Risk Rep 2012; 6:80-90.

116 Wiernsperger NF, Bouskela E: Microcirculation in insulin resistance and diabetes: more than just a complication. Diabetes Metab 2003;29(4 pt 2):6S77-6S87.

117 Hall JE, Summers RL, Brands MW, Keen H, Alonso-Galicia M: Resistance to metabolic actions of insulin and its role in hypertension. Am J Hypertens 1994;7:772-788.

118 Rao A, Pandya V, Whaley-Connell A: Obesity and insulin resistance in resistant hypertension: implications for the kidney. Adv Chronic Kidney Dis 2015;22:211-217.

119 Zhao L, Fu Z, Wu J, Aylor KW, Barrett EJ, Cao W, Liu Z: Inflammation-induced microvascular insulin resistance is an early event in diet-induced obesity. Clin Sci (Lond) 2015;129:1025-1036.
120 Singer G, Granger DN: Inflammatory responses underlying the microvascular dysfunction associated with obesity and insulin resistance. Microcirculation 2007; 14:375387.

121 Muris DM, Houben AJ, Schram MT, Stehouwer CD: Microvascular dysfunction: an emerging pathway in the pathogenesis of obesity-related insulin resistance. Rev Endocr Metab Disord 2013;14:29-38.

122 Hall JE, Brands MW, Zappe DH, Alonso Galicia M: Insulin resistance, hyperinsulinemia, and hypertension: causes, consequences, or merely correlations? Proc Soc Exp Biol Med 1995;208:317-329.

123 Karaca U, Schram MT, Houben AJ, Muris DM, Stehouwer CD: Microvascular dysfunction as a link between obesity, insulin resistance and hypertension. Diabetes Res Clin Pract 2014;103:382-387.

124 Oshitari T, Polewski P, Chadda M, Li AF, Sato T, Roy S: Effect of combined antisense oligonucleotides against high-glucose- and diabetes-induced overexpression of extracellular matrix components and increased vascular permeability. Diabetes 2006;55:86-92.

125 Bohlen HG: Mechanisms for early microvascular injury in obesity and type II diabetes. Curr Hypertens Rep 2004;6:60-65.

126 Detaille D, Guigas B, Chauvin C, Batandier C, Fontaine E, Wiernsperger N, Leverve X: Metformin prevents high-glucose-induced endothelial cell death through a mitochondrial permeability transition-dependent process. Diabetes 2005;54:2179-2187.

127 Navarro-Diaz M, Serra A, Romero R, Bonet J, Bayes B, Homs M, Perez N, Bonal J: Effect of drastic weight loss after bariatric surgery on renal parameters in extremely obese patients: long-term follow-up. J Am Soc Nephrol 2006;17(12 suppl 3):S213-S217.

128 Ikramuddin S, Korner J, Lee WJ, Connett JE, Inabnet WB, Billington CJ, Thomas AJ, Leslie DB, Chong K, Jeffery RW, Ahmed L, Vella A, Chuang LM, Bessler M, Sarr MG, Swain JM, Laqua P, Jensen MD, Bantle JP: Rouxen-Y gastric bypass vs intensive medical management for the control of type 2 diabetes, hypertension, and hyperlipidemia: the diabetes surgery study randomized clinical trial. JAMA 2013;309:2240-2249.

129 Gloy VL, Briel M, Bhatt DL, Kashyap SR, Schauer PR, Mingrone G, Bucher HC, Nordmann AJ: Bariatric surgery versus non-surgical treatment for obesity: a systematic review and meta-analysis of randomised controlled trials. BMJ 2013;347:f5934.

130 Virdis A, Neves MF, Duranti E, Bernini G, Taddei S: Microvascular endothelial dysfunction in obesity and hypertension. Curr Pharm Des 2013;19:2382-2389.

131 Winters B, Mo Z, Brooks-Asplund E, Kim S, Shoukas A, Li D, Nyhan D, Berkowitz DE: Reduction of obesity, as induced by leptin, reverses endothelial dysfunction in obese (Lep(ob)) mice. J Appl Physiol (1985) 2000; 89:2382-2390.
132 De Ciuceis C, Rossini C, Porteri E, La Boria E, Corbellini C, Mittempergher F, Di Betta E, Petroboni B, Sarkar A, Agabiti-Rosei C, Casella C, Nascimbeni R, Rezzani R, Rodella LF, Bonomini F, Agabiti-Rosei E, Rizzoni D: Circulating endothelial progenitor cells, microvascular density and fibrosis in obesity before and after bariatric surgery. Blood Press 2013;22:165-172.

133 Hall JE, Henegar JR, Dwyer TM, Liu J, Da Silva AA, Kuo JJ, Tallam L: Is obesity a major cause of chronic kidney disease? Adv Ren Replace Ther 2004;11:41-54.

134 Maric C, Hall JE: Obesity, metabolic syndrome and diabetic nephropathy. Contrib Nephrol 2011;170:28-35.

135 Pala L, Pezzatini A, Dicembrini I, Ciani S, Gelmini S, Vannelli BG, Cresci B, Mannucci E, Rotella CM: Different modulation of dipeptidyl peptidase- 4 activity between microvascular and macrovascular human endothelial cells. Acta Diabetol 2012;49(suppl 1):S59-S63.

136 Sachidanandam K, Hutchinson JR, Elgebaly MM, Mezzetti EM, Dorrance AM, Motamed $\mathrm{K}$, Ergul A: Glycemic control prevents microvascular remodeling and increased tone in type 2 diabetes: link to endothelin-1. Am J Physiol Regul Integr Comp Physiol 2009; 296:R952-R959.

137 Arunachalam G, Samuel SM, Marei I, Ding $\mathrm{H}$, Triggle CR: Metformin modulates hyperglycaemia-induced endothelial senescence and apoptosis through SIRT1. Br J Pharmacol 2014;171:523-535.

138 Takahashi N, Shibata R, Ouchi N, Sugimoto M, Murohara T, Komori K: Metformin stimulates ischemia-induced revascularization through an eNOS dependent pathway in the ischemic hindlimb mice model. J Vasc Surg 2015;61:489-496.

139 Renaudin C, Michoud E, Rapin JR, Lagarde $\mathrm{M}$, Wiernsperger N: Hyperglycaemia modifies the reaction of microvessels to insulin in rat skeletal muscle. Diabetologia 1998;41: 26-33.

140 Huri HZ, Lim LP, Lim SK: Glycemic control and antidiabetic drugs in type 2 diabetes mellitus patients with renal complications. Drug Des Devel Ther 2015;9:43554371.

141 Huri HZ, Ling DY, Ahmad WA: Association between glycemic control and antidiabetic drugs in type 2 diabetes mellitus patients with cardiovascular complications. Drug Des Devel Ther 2015;9:4735-4749.

142 Kurtz TW: False claims of blood pressureindependent protection by blockade of the renin angiotensin aldosterone system? Hypertension 2003;41:193-196.

143 Blanco S, Vaquero M, Gomez-Guerrero C, Lopez D, Egido J, Romero R: Potential role of angiotensin-converting enzyme inhibitors and statins on early podocyte damage in a model of type 2 diabetes mellitus, obesity, and mild hypertension. Am J Hypertens 2005; 18:557-565. 
$144 \mathrm{He}$ H, Yang D, Ma L, Luo Z, Ma S, Feng X, Cao T, Yan Z, Liu D, Tepel M, Zhu Z: Telmisartan prevents weight gain and obesity through activation of peroxisome proliferator-activated receptor-delta-dependent pathways. Hypertension 2010;55:869-879.

145 Mori Y, Tanaka T, Matsuura K, Yokoyama J, Utsunomiya K: Influence of telmisartan on insulin response after glucose loading in obese patients with hypertension: ARB trial of hypertension in obese patients with hyperinsulinemia assessed by oral glucose tolerance test (ATHLETE). Adv Ther 2011;28: 698-706.

146 Liao JK, Laufs U: Pleiotropic effects of statins. Annu Rev Pharmacol Toxicol 2005; 45:89-118.

147 Zhou Q, Liao JK: Pleiotropic effects of statins - basic research and clinical perspectives. Circ J 2010;74:818-826.

148 Chade AR, Zhu X, Mushin OP, Napoli C, Lerman A, Lerman LO: Simvastatin promotes angiogenesis and prevents microvascular remodeling in chronic renal ischemia. FASEB J 2006;20:1706-1708.
149 Lavi R, Zhu XY, Chade AR, Lin J, Lerman A, Lerman LO: Simvastatin decreases endothelial progenitor cell apoptosis in the kidney of hypertensive hypercholesterolemic pigs. Arterioscler Thromb Vasc Biol 2010;30:976983.

150 Zhu XY, Daghini E, Chade AR, Napoli C, Ritman EL, Lerman A, Lerman LO: Simvastatin prevents coronary microvascular remodeling in renovascular hypertensive pigs. J Am Soc Nephrol 2007;18:1209-1217.

151 Yin J, Lee JH, Zhang J, Gao Z, Polotsky VY, Ye J: Regulation of hepatocyte growth factor expression by NF- $\kappa B$ and PPAR $\gamma$ in adipose tissue. Am J Physiol Endocrinol Metab 2014; 306:E929-E936.

152 Chade AR, Stewart N: Angiogenic cytokines in renovascular disease: do they have potential for therapeutic use? J Am Soc Hypertens 2013;7:180-190.
153 Stewart N, Chade AR: Renoprotective effects of hepatocyte growth factor in the stenotic kidney. Am J Physiol Renal Physiol 2013; 304:F625-F633.

154 Neuss S, Becher E, Woltje M, Tietze L, Jahnen-Dechent W: Functional expression of HGF and HGF receptor/c-met in adult human mesenchymal stem cells suggests a role in cell mobilization, tissue repair, and wound healing. Stem Cells 2004;22:405414

155 Park BY, Lee H, Woo S, Yoon M, Kim J, Hong Y, Lee HS, Park EK, Hahm JC, Kim JW, Shin SS, Kim MY, Yoon M: Reduction of adipose tissue mass by the angiogenesis inhibitor ALS-L1023 from melissa officinalis. PLoS One 2015;10:e0141612.

156 Flegal KM, Kalantar-Zadeh K: Overweight, mortality and survival. Obesity (Silver Spring) 2013;21:1744-1745.

157 Flegal KM, Kit BK, Orpana H, Graubard BI: Association of all-cause mortality with overweight and obesity using standard body mass index categories: a systematic review and meta-analysis. JAMA 2013;309:71-82. 